\title{
Curriculum Reform and Practice of Architectural Engineering: Based on Architectural CAD
}

\author{
Yajuan Liu* \\ Chongqing Energy College, Chongqing 402260, China \\ *Corresponding author: Yajuan Liu, liuyajuan_0510@163.com
}

\begin{abstract}
Architectural CAD is the core course of Engineering Cost Specialty in higher vocational colleges. If students can gradually develop the ability of architectural drawing recognition and drawing when learning this course, they can lay a foundation for better work after graduation. This paper expounds the nature of Architectural CAD and the significance of cultivating architectural drawing recognition ability of students based on Architectural CAD course, and analyze the strategy of cultivating architectural drawing recognition ability of students based on Architectural CAD course.
\end{abstract}

Keywords: Architectural CAD; Architectural drawing recognition ability; Significance; Strategy

Publication date: September 2021; Online publication: September 30, 2021

\section{Introduction}

The popularization of higher education makes graduates face severe employment pressure after graduation. Due to the limited knowledge, they have learned in colleges and universities, many graduate students are unable to engage in their major after graduation. The reason has a great deal to do with the lack of pertinence and practicability of talent training in colleges and universities. Many colleges and universities are teaching mainly based on basic courses + practical courses + internship, and the study of the whole course does not combine with the actual phenomenon of the society. For example, one course of architectural engineering is Architectural CAD, which spans the knowledge of architectural design, structural design, architectural construction and many other fields. It is a very practical course. When teaching such courses, some teachers focus on the transmission of knowledge and ignore the cultivation of students' architectural drawing recognition ability, which also leads to a gap between the trained talents and the talents needed by the industry, affecting the employment rate of colleges and universities.

\section{Nature of Architectural CAD courses}

Architectural CAD is a required professional technical basic course for various majors such as construction, cost, civil engineering and decoration, which has strong practicality. It is the combination of traditional architectural system and information drawing software AutoCAD. It is the main technical basic course for building engineering to cultivate applied talents. By studying this kind of courses, students can master basic methods and principal of drawing architectural drawings with AutoCAD, master the industry drawing specifications and be able to expertly draw architectural general drawing, elevation drawing and floor plan ${ }^{[1]}$. Architectural CAD course system includes drawing and editing plane graphics, AutoCAD operation basis and setting, drawing and editing professional engineering drawings, drawing and editing threedimensional graphics. No matter what knowledge is learned, it actually is inseparable from the students' spatial imagination ability and the ability to recognize pictures. 
3. The significance of cultivating students' ability of architectural drawing recognition ability based on Architectural CAD course

\subsection{It is conductive to help students lay a good foundation for architectural CAD course}

Architectural CAD is a subject with strong theory and practice. It is a computer-aided design technology that architectural engineering students must master. Looking at many colleges and universities at present, when carrying out the course of architectural CAD, they mainly focus on explaining drawing and structure, and allow students to use drawing software to draw a variety of three-dimensional solid drawings, detailed drawings, plans, etc. on the whole, which is lack of combination with drawing recognition ability. By integrating the cultivation of students' architectural drawing recognition ability into the architectural CAD course, students need to be able to understand the drawing software. Let students master the basic drawing recognition ability before drawing, and gradually lay a good foundation for the architectural CAD course.

\subsection{It is conducive to changing the traditional single teaching mode}

In traditional colleges and universities, when carrying out architectural CAD courses, students are usually taught and demonstrated to master the relevant CAD software and operation methods. Although this means can make the information transmission more intuitive, it lacks the initiative of independent and cooperative learning among students in the classroom. Sometimes, in most of the teaching time, students are looking at pictures and words. The knowledge points are not coherent and easy to be forgotten. And in the process of demonstration, students cannot get training, which cannot cultivate students' drawing recognition ability. By integrating the ability of drawing recognition into architectural CAD, it is necessary to innovate the traditional simple teaching and demonstration mode. Through the problem guidance method, group cooperation method, case analysis and other modes, students can identify the relevant graphics of architecture, which greatly improves the efficiency of students' learning in architectural CAD ourse ${ }^{[2]}$.

\subsection{It is conducive to improving the employment rate of construction engineering}

With the rapid development of information technology, CAD is more and more widely used in the field of construction engineering, and improves the quality of construction engineering and construction design drawing. However, in addition to drawing, architectural CAD also includes the ability of drawing recognition. By combining drawing and drawing recognition, it is conducive to improve the teaching quality of architectural CAD course and provide guarantee for the employment rate of architectural engineering major in colleges and universities.

\section{The strategy of cultivating students' ability of architectural drawing recognition ability based on Architectural CAD course}

Architectural CAD course is a very basic and important course for architectural engineering specialty. This kind of course requires students to master drawing software and be able to recognize and draw drawings. Among them, the ability to recognize drawings is a very important ability in the architectural CAD course, and it is also the basis for students' drawing and learning. The following is gradually implemented students' ability to recognize drawings and improve the quality of architectural CAD course teaching mainly from three angles: Micro class, case teaching method and practice exercises.

\subsection{Display the basic knowledge of drawing based on micro course teaching to enhance students' interest in drawing recognition}

Interest is the internal driving force of students' learning. As far as the course of architectural CAD is concerned, it has a lot of content and is very boring. Many professional knowledge is difficult to achieve a good learning effect only by teachers' dictation, and it is also difficult to mobilize students' interest in map 
reading. Therefore, teachers need to integrate diversified teaching methods to attract students' active participation. Micro class is characterized by brevity and refinement. It can show students key knowledge in a short time and enhance students' interest in learning. For example, there are many basic knowledge in architectural CAD. Teachers can use micro classes to show the process of setting layers, and let students analyze the name, width and type of line type in soil layer through observation and thinking. By showing the dimension style, let students find out the datum and constituent elements of the dimension. By showing the actual content in micro class, attract students to observe, analyze, think and summarize, so as to gradually enhance students' interest in map reading.

\subsection{Cultivate students' spatial imagination by the combination of case teaching method and problem teaching method}

The course of architectural CAD emphasizes practicality and mastery, that is, as long as students are provided with drawing steps and handling methods of common problems, students can work. Through the analysis of typical examples, mining software drawing function, and mastering drawing skills, it also can promote students to continue to complete the task of practical training. In order to cultivate students' drawing recognition ability in architectural CAD course, it is necessary to improve students' spatial imagination. For example, in the process of classroom teaching, build a real scene of professional activities for students, including architectural plans, elevations, sections and node details. In the teaching project, take the development process of professional work as the teaching order, reasonably put forward questions, guide students to analyze the drawing methods and steps of plan and elevation, and realize the integration of drawing methods and AutoCAD commands. Of course, in this process, teachers should let students imagine the steps and processes of drawing in their minds, and verify their imagination in continuous practice, so as to lay a foundation for improving students' drawing ability while mastering drawing skills.

\subsection{Improve students' ability to read drawings based on AutoCAD software assisted exercises}

In the course of architectural CAD, if a teacher wants to improve students' drawing ability, he should not only guide them through micro class teaching and case teaching method, but also use the auxiliary exercises of AutoCAD software to enable students to master the drawing principle and improve their drawing ability in the process of drawing practice. However, the traditional after-school exercises are mainly based on offline drawing. Teachers need to spend a lot of energy correcting students' homework. After homework correction, students often do not take the initiative to correct mistakes, and the overall teaching quality is not high. By integrating AutoCAD software into it, the original problems can be better solved. After class, students can draw freely according to AutoCAD software and understand the drawing skills. For example, in the process of drawing a plan, one part is connected by an arc, assuming R40 and R15. When connecting, it is necessary to determine the arc of R40 and the arc center of R15. There will be errors only through the observation of the sample drawing, just like a point. Using software drawing, students can zoom and find the problem of drawing by yourself. And through the observation and understanding of the whole graph, students can understand the correct drawing operation ${ }^{[3]}$. In the whole process of drawing practice, students need to first understand and deeply analyze the known and unknown conditions of the subject, and carefully observe the drawing while drawing, which virtually improves students' drawing ability.

\section{Conclusion}

In a word, architectural drawing recognition is the foundation for architecture related majors. Only by mastering the ability of architectural drawing can students gradually improve their professional skills and let students develop continuously on the road of the major. 


\section{Disclosure statement}

The author declares no conflict of interest.

\section{References}

[1] Fan YJ, 2020, Practice and Exploration of Teaching Reform of Architectural Drawing Recognition and Construction Course Based on Post Ability. The Farmers Consultant, 4(01): 240.

[2] Yang F, 2019, Research on the Integration Course Construction of Architectural Drawing Recognition and CAD Drawing Based on Working Process. Journal of Tongling Vocational \& Technical College, 18(01): 90-94+100.

[3] Chen JH, 2019, Teaching Reform of Architectural Map Recognition Course based on Cultivation of Architectural Drawing Recognition Ability. Modern Vocational Education, 4(06): 190-191. 